\title{
ESPÉCIES COM PRINCÍPIOS TÓXICOS, EMPREGADOS NA ARBORIZAÇÃO URBANA DO BAIRRO NOSSA SENHORA DAS GRAÇAS-MIGUELÓPOLIS, SP
}

\begin{abstract}
MEDEIROS, Luiz Fernando Souza ${ }^{74}$
PEREIRA, Márcio ${ }^{75}$
\end{abstract}

Recebido em:2008-06-19

Aprovado em: 2008-09-12

ISSUE DOI: $10.3738 / 1982.2278 .103$

RESUMO: Este trabalho foi desenvolvido, em área urbana no município de Miguelópolis-SP, no período de agosto 2007 a fevereiro de 2008, O presente trabalho teve como objetivo identificar e catalogar as espécies de vegetais com princípio tóxico, na área urbana do município de Miguelópolis-SP, levando em consideração a descrição dos aspectos das plantas tóxicas, como forma de orientar a população dos perigos de intoxicação. Os casos de intoxicação que têm mais chamado atenção em animais domésticos (cães e gatos), bem como em seres humanos, sobretudo crianças, ocorrem quando esses ingerem pequenas quantidades (folhas, talos, flores, frutos ou sementes) de plantas de fácil alcance, de alta toxidez ou irritantes, entre elas, plantas ornamentais. Em todas as ruas trabalhadas, foram encontradas espécies tóxicas. Sendo que a rua - José Zuquim Nogueira foi a de maior ocorrência, num total de 05 espécies. As espécies comuns nas ruas vistoriadas foram: Dieffenbachia picta Schot, Conhecida popularmente como "Comigo ninguém pode" e Alamanda cathartica, conhecida como "Alamanda amarela". A importância de se fazer estudos em ruas garantem um cuidado maior para o processo de arborização da cidade.

Palavras-chave: Plantas tóxicas. Intoxicação. Ruas.

\section{SPECIES WITH PRINCIPLES TOXIC, ARBORIZAÇÃO EMPLOYEES IN URBAN NEIGHBORHOOD OF OUR LADY OF GRAÇAS, MIGUELÓPOLIS-SP}

SUMARY: This work was developed in the urban area in the municipality of Miguelópolis-SP, in the period from August 2007 to February 2008, this work was to order prioritize remarks study of toxic plants in the neighborhood of Our Lady Thanks, with the goal the description of aspects of toxic plants and as a way to guide the population, the dangers of intoxication. The cases of intoxication that are more pointed in domestic animals (dogs and cats) as well as in humans, especially children, these occur when eating small amounts (leaves, stems, flowers, fruits or seeds) of plants within easy reach, high toxicity or irritants, including ornamental plants. On every street, worked were found toxic species. Since the street - Zuquim Jose Nogueira was the largest of occurrence, a total of 05 species. The species common in the streets vistoriadas were:Dieffenbachia picta Schot, Better known as Comigo and

\footnotetext{
${ }^{74}$ Esp. Em Agronegócio e Desenvolvimento Sustentável. Licenciatura Plena em Ciências Biológicas. FFCL/ Faculdade de Filosofia Ciências e Letras de Ituverava-SP. candelabrio8@ hotmail.com

${ }^{75}$ Dr. em Recursos Florestais / Diretor da Faculdade Dr. Francisco Maeda. Fundação Educacional de Ituverava. marciopereira@feituverava.com.br
} 
nobody can Alamanda cathartica, know nas Yellow Alamanda.The importance of doing studies in streets ensure a greater attention to the process of afforestation of the city.

Keywords: Toxic plants. Intoxication. Streets.

\section{INTRODUÇÃO}

Os centros urbanos, segundo Milano (1988), já abrigam mais de 43\% da população mundial e esse percentual tende a aumentar, observando-se o modo de vida atual dos países mais desenvolvidos.

O impacto ambiental originado pela expansão das cidades pode ser minorado através de um plano de arborização urbana. Diferentes autores (DETZEL, 1992; MILANO, 1992; PALERMO JR., 1985; SANCHOTENE, 1994, 2000; SANTOS e TEIXEIRA, 2001; SATTLER, 1992; SILVA, 1987) destacaram importâncias da sua implantação e manutenção, tais como: conforto para a cidade, purificação do ar, equilíbrio térmico, redução de ruídos, qualificação financeira e paisagística de um imóvel, atração de fauna e flora silvestres, opções de lazer e descanso para a população e valorização histórico-cultural.

Foram desenvolvidos diversos estudos sobre arborização urbana em cidades brasileiras. Palermo Júnior (1985), trata do planejamento e interferência da arborização sobre a fiação e sugere o uso de frutíferas nativas e o controle biológico de pragas, desaconselhando a poda drástica. Junto ao crescente estudo das plantas estão o interesse e o conhecimento sobre seus componentes químicos.

Assim, são descobertas não só as plantas medicinais, úteis para a manutenção da saúde e da qualidade de vida, como também, as plantas tóxicas. Essas, temidas por muitos e mal utilizadas por outros, costumam ser belas, com suas flores coloridas e atrativas, trazendo um grande risco às pessoas que as desconhecem (BARG, 2004).

A grande maioria das plantas de jardim com princípios tóxicos provocam reações na pele e mucosas (principalmente aquelas que secretam leite ou látex), as outras, produzem distúrbios no aparelho cardiovascular e gastrintestinal. Felizmente, a maioria das plantas consideradas nocivas possui um paladar desagradável, esencorajando as pessoas a ingerir tais 
vegetais (o mesmo não se aplica às crianças e animais de estimação) (CIAVE, 2000).

Segundo Haraguchi (2003), denominam-se plantas tóxicas todo vegetal que, introduzido no organismo humano ou de animais domésticos, em condições naturais, é capaz de causar danos que se refletem na saúde e na vitalidade desses seres.

Elas ocasionam um desequilíbrio que se traduz no paciente sintomas de intoxicação. Assim, como toda planta é potencialmente tóxica e uma planta identificada como tóxica ocasiona um desequilíbrio que se traduz no indivíduo como sintoma de intoxicação, é de suma importância a catalogação destas espécies em ambientes que são considerados de lazer pela população, como as praças e ruas públicas.

\section{MATERIAL E MÉTODO}

\section{Caracterização da área de estudo}

O estudo foi realizado no bairro Nossa Senhora das Graças, município de

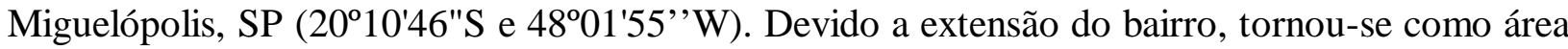
de estudo 5 Ruas: José Zuquim Nogueira, Otaviano Trindade, Landulfo Alves de Freitas, Joaquim Pedro Figueredo, Yoshi Nomyama, com população média de 1.730 habitantes, foi utilizado o mapa do bairro para facilitar o estudo das ruas.

Foram coletados dados, elaborando uma ficha da arborização urbana. Os itens levantados foram os seguintes:

a) nome popular; b)nome cientifico; c) família botânica; d) princípio ativo; e) parte tóxica. Os dados obtidos em campo foram plotados em tabelas para posterior análise. 


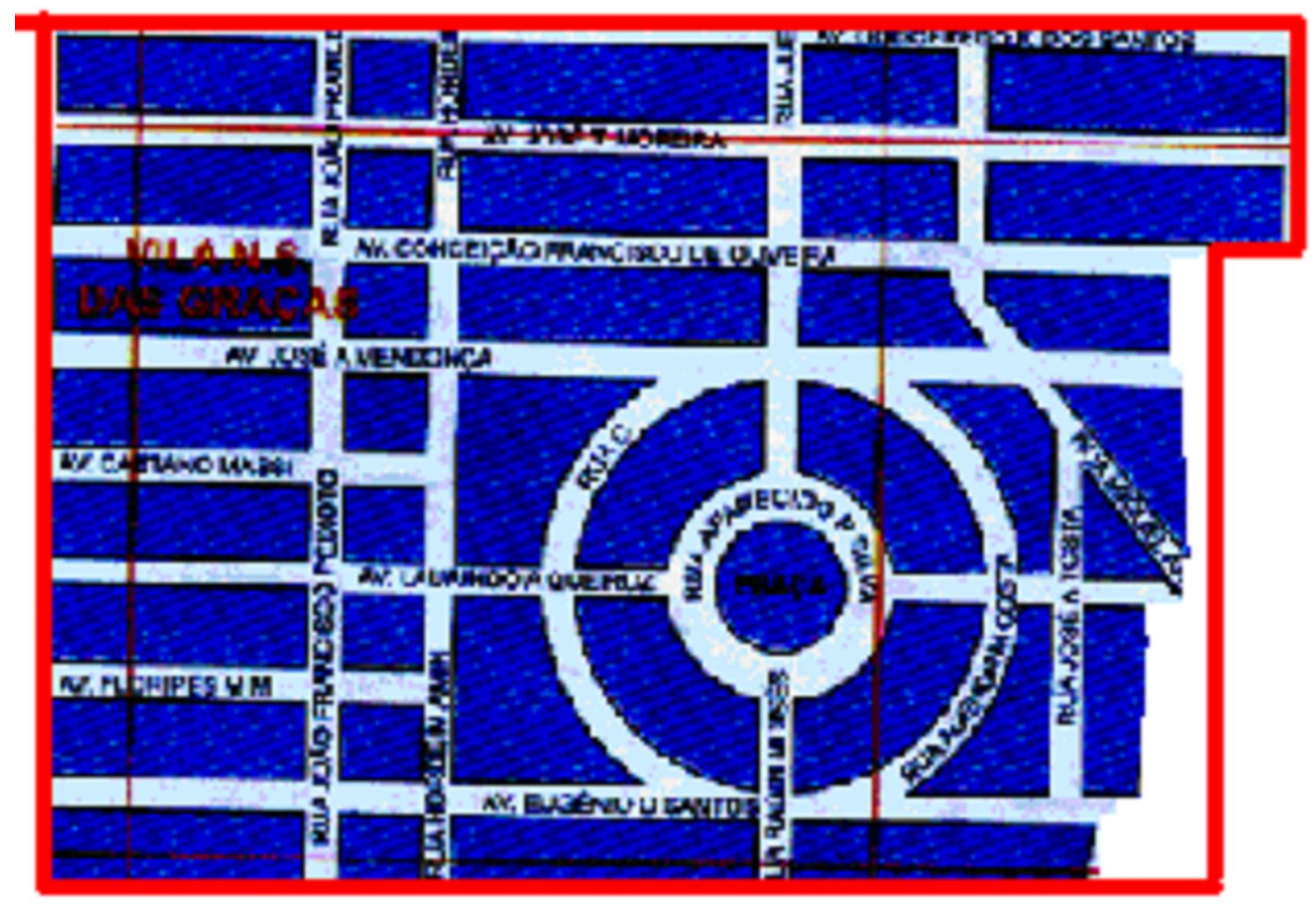

Figura 1: Área de Estudo Bairro Nossa Senhora das Graças

\section{RESULTADO E DISCUSSÃO}

Foram amostradas 72 plantas em 05 ruas, distribuídas em 7 famílias Apocynaceae foi a família que apresentou maior número de espécies (04), seguida por Araceae com três espécies. Algumas espécies encontradas são desaconselhadas para o plantio em vias públicas por serem eventualmente tóxicas aos pedestres, (SANTOS; TEIXEIRA, 2001), entre elas a espirradeira (Nerium oleander L.).

Essas espécies poderiam ser substituídas por outras de porte semelhantes e úteis a fauna. Com os resultados deste trabalho, sugere-se a elaboração de um programa de conscientização sobre o uso plantas tóxicas na arborização urbana tanto aos moradores quanto às empresas que desenvolvem projetos de arborização de praças e vias públicas. 
Tabela 1: Espécies tóxicas encontradas na arborização urbana do Bairro Nossa Senhora das Graças, Miguelópolis, SP.

\begin{tabular}{lllll}
\hline Nome Comum & Nome Científico & Família Botânica & Princípio & Ativo Parte Tóxicas \\
\hline Alamanda-amarela & Alamanda cathartica & Apocynaceaee & Toxalbumina ( ricina) & Todas as partes da planta \\
Antúrio, Flor de verniz & Anthurium & Araceae & Oxalato de cálcio & Todas as partes da planta \\
Comigo ninguém pode & Dieffenbachia picta Schot & Araceae & Oxalato de cálcio & Todas as partes da planta \\
Chapéu de Napoleão & Thevetia peruviana $S$. & Apocynaceae & Glicosideos Cardiotóxicos & Todas as partes da planta \\
Costela-de-adão & Monstera deliciosa & Araceae & Oxalato de cálcio, saponinas & Todas as partes da planta \\
Espirradeira & Nerium oleander & Apocynaceae & Glicosideos Cardiotóxicos & Todas as partes da planta \\
Jasmim-manga & Plumeria rubra & Apocynaceae & Agoniadina (alcalóide) & Todas as partes da planta \\
Mamona & Ricinus communis $L$. & Euphorbiaceae & Toxalbumina ( ricina) & Sementes \\
Pinhão-roxo & Fleurya aestuans $L$. & Euphorbiaceae & Toxalbumina ( ricina) & Folhas e frutos \\
Urtiga & Fleurya aestuans $L$. & Urticaceae & Histamina, acetilcolina & Pelos do caule e folha \\
& & & & \\
\hline
\end{tabular}


Tabela 2: através desta Tabela venho demonstrar a toxicidade e a quantidade de plantas tóxicas encontradas no Bairro Nossa Senhora das Graças, onde foi realizado o levantamento dessas plantas.

Vias Públicas e Praças Quantidade de plantas encontradas

Nome Popular da planta

José Zuquim Nogueira

José Zuquim Nogueira

José Zuquim Nogueira

José Zuquim Nogueira

José Zuquim Nogueira

Joaquim Pedro Figueredo

Joaquim Pedro Figueredo

Landulfo Alves de Freitas

Landulfo Alves de Freitas

Landulfo Alves de Freitas

Otaviano Trindade

Otaviano Trindade

Otaviano Trindade

Yoshi Nomyama

Yoshi Nomyama

Yoshi Nomyama

Total de ruas: 05

04

03

06

06

03

10

04

03

02

03

08

01

03

05

06

05

Total de plantas: 72
Costela de Adão

Chapéu de Napoleão

Alamanda - amarela

Comigo ninguém pode

Antúrio

Comigo ninguém pode

Espirradeira

Jasmim Manga

Antúrio

Pinhão Roxo

Comigo ninguém pode

Urtiga

Mamona

Chapéu de Napoleão

Comigo ninguém pode

Alamanda - amarela 
Fotos das Plantas encontradas na arborização de praças e vias públicas no bairro nossa Senhora das Graças, em Miguelópolis-SP.

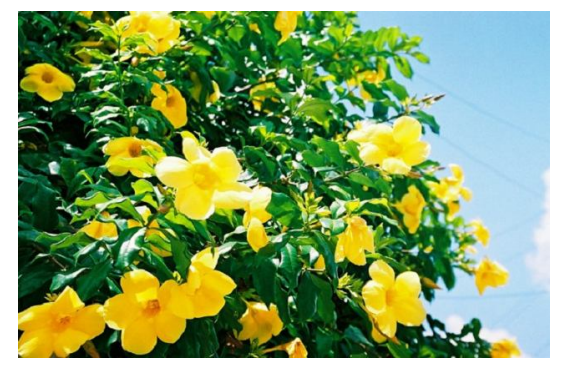

Nome popular: Alamanda -amarela

Nome científico: Allamanda cathartica $L$.

Família: Apocynaceae

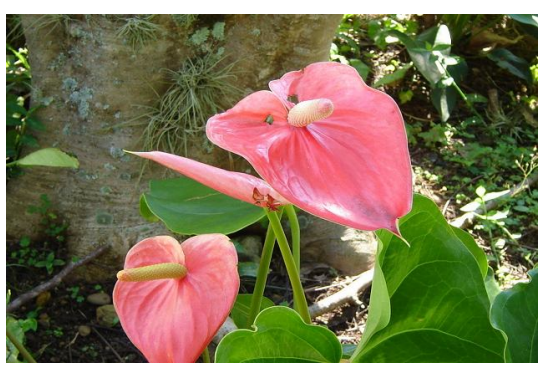

Nome popular: Antúrio

Nome científico: Anthurium andraeanum

Família: Araceae

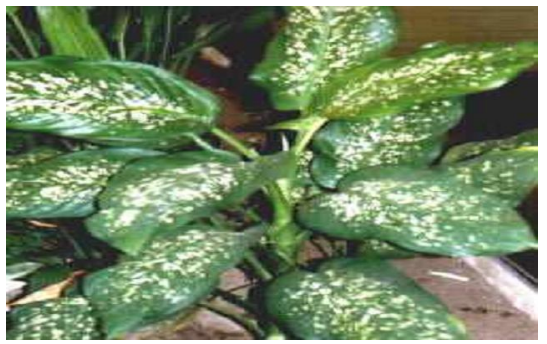

Nome popular: Comigo ninguém pode

Nome Científico: Dieffenbachia picta Schott

Família : Araceae

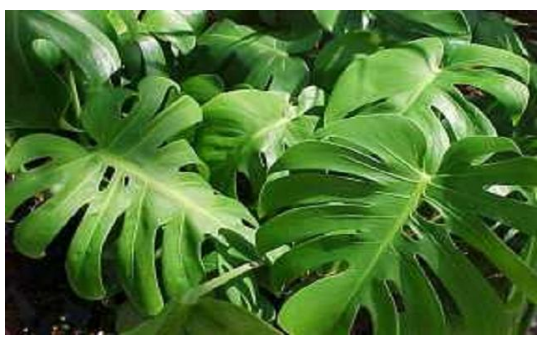

Nome popular: Costela de Adão

Nome científico: Monstera deliciosa

Família : Araceae

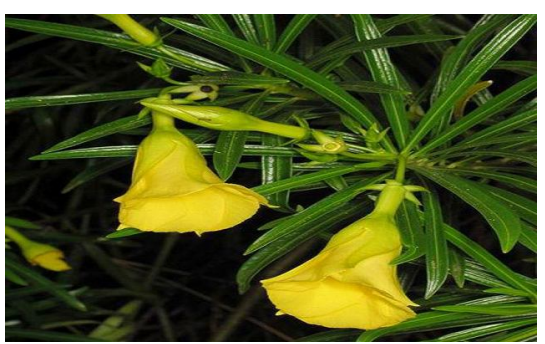

Nome popular: Chapéu de Napoleão

Nome científico: Thevetia peruviana Schum.

Família : Apocynaceae 

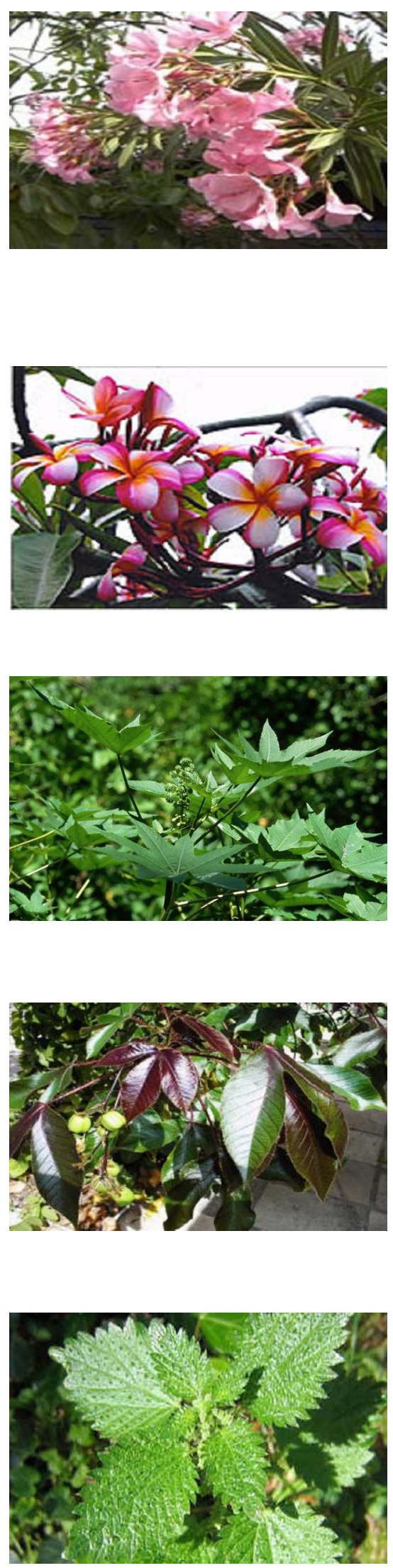

Nome popular: Espirradeira

Nome científico: Nerium oleander L

Família : Apocynaceae

Nome popular: Jasmim Manga

Nome científico: Plumeria rubra

Família : Apocynaceae

Nome popular: Mamona

Nome científico: Ricinus communis L

Família : Euphorbiaceae

Nome popular: Pinhão roxo

Nome científico: Jatropha curcas L.

Família : Euphorbiaceae

Nome popular: Urtiga

Nome científico: Fleurya aestuans L.

Família : Urticaceae 
Gráfico de plantas Tóxicas encontradas nas ruas do bairro Nossa Senhora das Graças

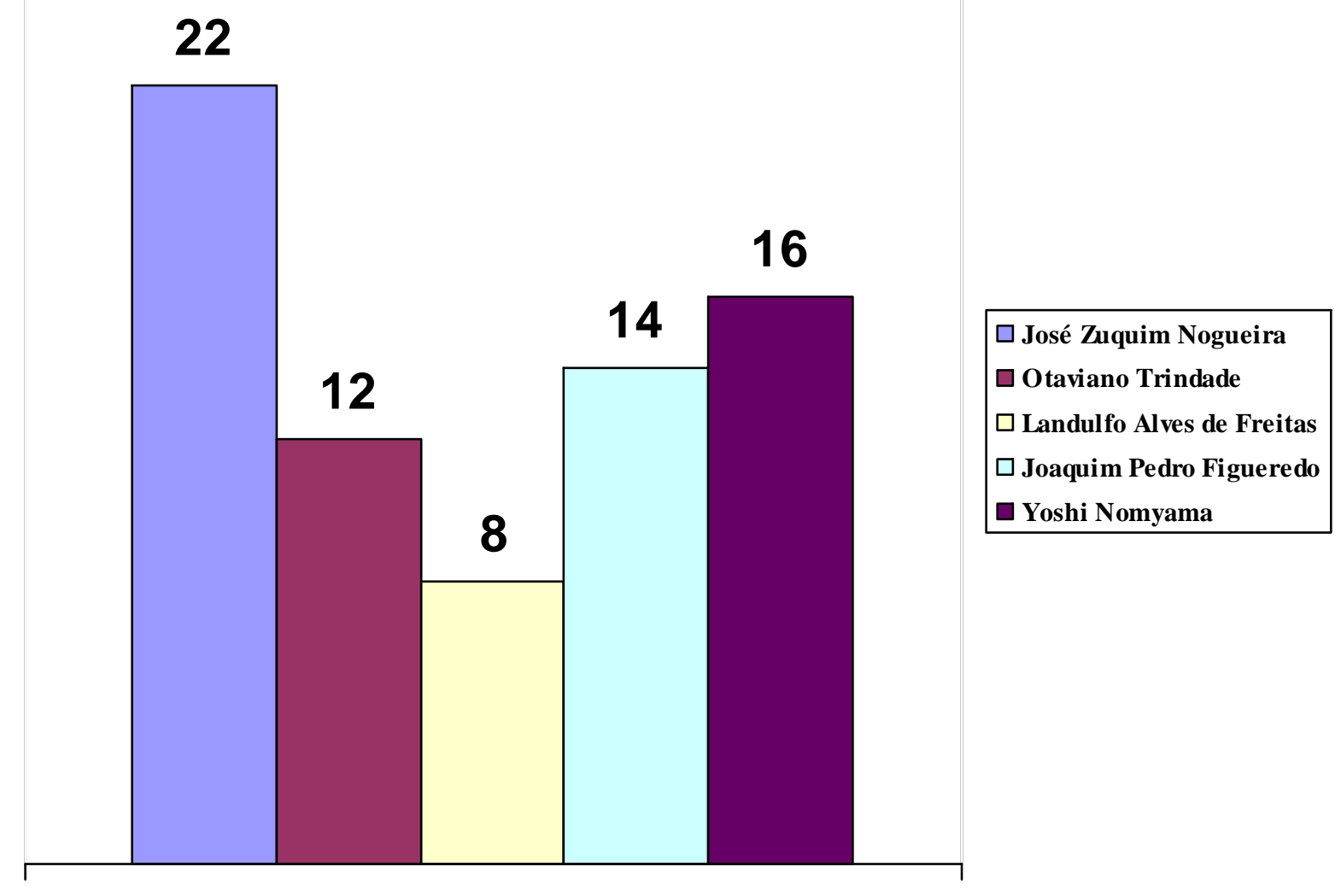

Número de plantas encontradas

Figura 1: Percentual de espécies tóxicas componentes da arborização urbana nas Ruas do Bairro, Nossa Senhora das Graças, Miguelópolis - SP- 2008. 


\section{Plantas tóxicas encontradas no bairro Nossa Senhora das Graças Miguelópolis-SP}

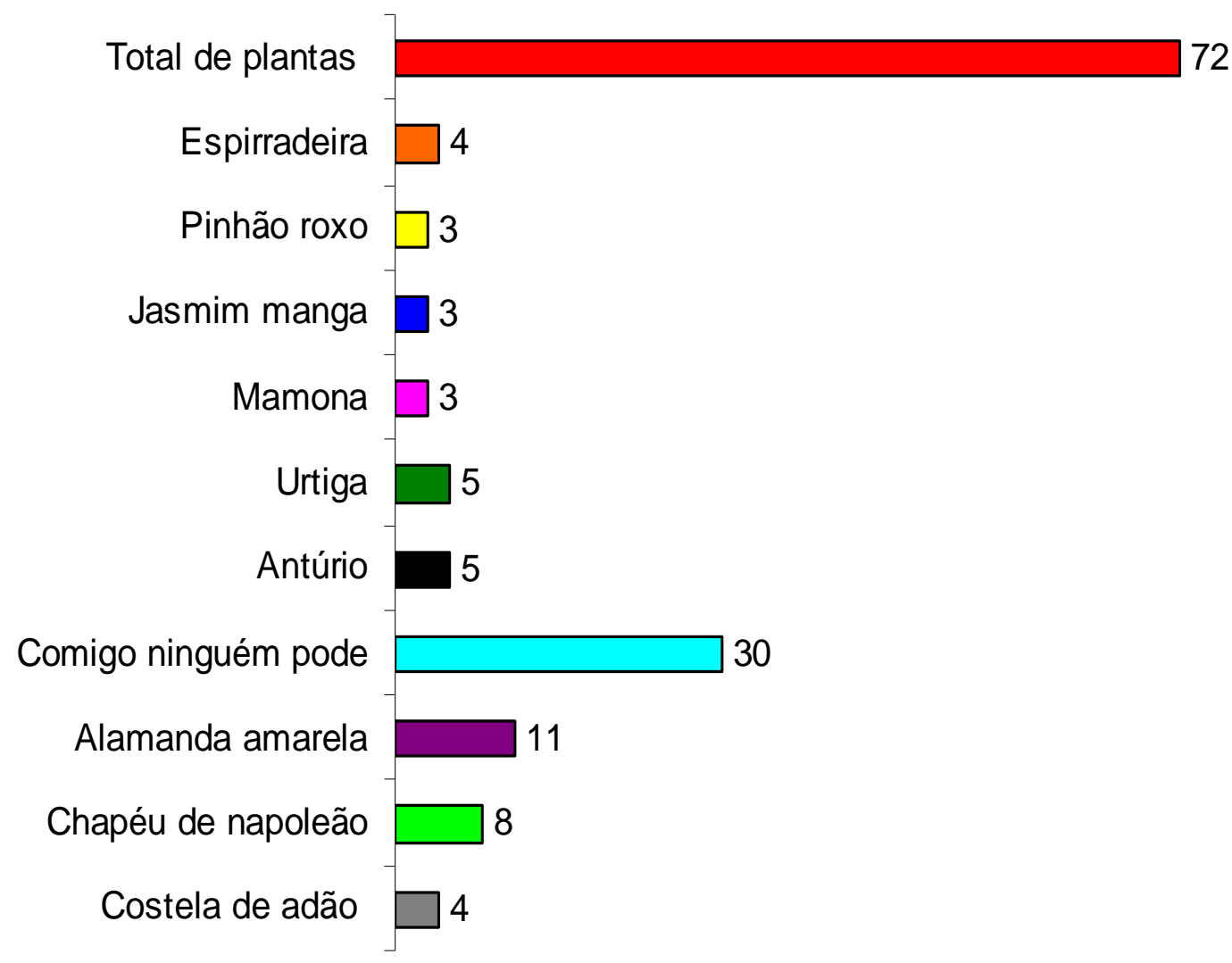

Figura 2: Gráfico de plantas encontradas no bairro nossa senhora das graças.

\section{CONCLUSÃO}

Através deste trabalho, pode-se concluir que existe um número elevado de espécies vegetais com princípio tóxico na área urbana no município de Miguelópolis-SP. Sugere-se a substituição dos exemplares que apresentem princípios tóxicos, por espécies mais adequadas às condições da arborização do Bairro.

\section{REFERÊNCIAS}

BARG, D. G. Plantas tóxicas. Instituo Brasileiro de Estudos Homeopáticos - Faculdade de Ciências da Saúde de São Paulo, 2004. 23p. 
CIAVE-Centro de informações antiveneno da Bahia. Jardim de plantas tóxicas. Secretaria da Saúde do Estado da Bahia, 2000. Disponível $\mathrm{em}:\langle$ http://www.saude.ba.gov.br/ciave/jardim.asp $>$. Acesso em 02 mar. 2007.

CRUZ, T.C. ; PARDAL, P. P. O. Perfil epidemiológico das plantas tóxicas no município de Belém, no período de julho de 2004 a agosto de 2005. Disponível em:

$<$ http://www.saudebrasilnet.com.br/premios/saude/premio4/trabalhos/031.pdf $>$ Acesso em 06 mar. 2007.

DETZEL, V. A. Arborização urbana: importância e avaliação econômica. In: CONGRESSO BRASILEIRO DE ARBORIZAÇÃO URBANA, 1, 1992, Vitória. Anais... Vitória: Prefeitura Municipal de Vitória, 1992. p.39-52.

HARAGUCHI, M. Plantas tóxicas de interesse na pecuária. Biológico, São Paulo, v.65, n. 1/2:37-39, 2003

MILANO, M. S. A cidade, os espaços abertos e a vegetação. In: CONGRESSO BRASILEIRO DE ARBORIZAÇÃO URBANA, 1, 1992, Vitória. Anais... Vitória: Prefeitura municipal de Vitória, 1992. p. 3-14.

PALERMO JR. A Arborização. 2 ed., São Paulo: CESP, 1985. 19 p. (Ecossistemas terrestres).

SINITOX - Sistema Nacional de Informações Tóxico-Farmacológicas. Plantas tóxicas no Brasil, 2004. Disponível em: <http://www.fiocruz.br/sinitox/plantas.htm>Acesso em 18 mar. 2007.

SANCHOTENE, M. C. C. Desenvolvimento e perspectivas da arborização urbana no Brasil. In: CONGRESSO BRASILEIRO DE ARBORIZAÇÃO URBANA, 2, 1994, São Luís. Anais... São Luís, 1994, p. 15-25.

SANTOS, N. R. Z; TEIXEIRA, I. F. Arborização de vias públicas: ambiente x vegetação. Santa Cruz do Sul: Instituto Souza Cruz, 2001.135 p.

SATTLER, M. A. Arborização urbana e conforto ambiental. In: CONGRESSO BRASILEIRO DE ARBORIZAÇÃO URBANA, 1, 1992, Vitória. Anais... Vitória: Prefeitura municipal de Vitória, 1992. p.15-28. 
Nucleus, v.5, n.2, out. 2008 